\title{
When Is Inequality Fair?
}

\section{Gideon Elford ${ }^{1}$}

Accepted: 20 November 2018 / Published online: 4 December 2018

(C) The Author(s) 2018

\begin{abstract}
Recent literature on responsibility-sensitive egalitarianism has suggested that an opposition to unchosen inequality on the grounds of unfairness is compatible with a range of accounts as to which inequalities are fair. I argue that forms of responsibility-sensitive egalitarianism face a challenge in the construction of such accounts; namely to explain the fairness of such inequalities specifically, as opposed to their being merely justified in a broader sense. I illustrate the nature of this challenge through an interesting parallel with an issue in value theory in the form of the so-called 'wrong kind of reason' problem.
\end{abstract}

Keywords Equality $\cdot$ Inequality $\cdot$ Fairness $\cdot$ Luck egalitarianism $\cdot$ Responsibility $\cdot$ Desert

Over the past quarter of a century egalitarian theory has moved to interpret the value of equality in a way that takes account of the significance of responsibility (Dworkin 1981; Cohen 1989; Arneson 1989). A great number of the most prominent egalitarian positions have argued not for strict equality but in favour of an understanding of the value of equality under which people's choices make a difference to what they are owed. In taking such a position egalitarian authors have maintained that, far from being antithetical to one another, a proper understanding of equality entails rather than conflicts with considerations of responsibility, and commends rather than eschews certain inequalities, specifically those that in some way reflect people's responsible choices. Indeed, in what has increasingly become the paradigm reference point with which to trace the evolution of egalitarian ideas in this regard, Cohen $(1989,933)$ credits Ronald Dworkin with having "performed for egalitarianism the considerable service of incorporating within it the most powerful idea in the arsenal of the anti-egalitarian right: that of choice and responsibility."

One of the stronger would-be anti-egalitarian objections to equality tout court appears to be one of fairness. It just wouldn't be fair, this line of thought runs, to demand equality between persons when some of those persons are hard-working and prudent whereas others are lazy or

Gideon Elford

Gideon.elford@new.ox.ac.uk

$1 \quad$ New College, Oxford OX1 3BN, UK 
reckless. The Dworkin-inspired egalitarian answer to this has been to discriminate between factors for which individuals are and are not responsible, and to demand equality only in the space of the latter. Accordingly, on such a view, the proper understanding of equality avows equal opportunities, in contrast to equal outcomes, and allows inequalities where individuals can be appropriately be held responsible for them. Inequality is permitted but fairness is preserved because the inequality in question is connected in the right ways to the responsibility of those who are better or worse off.

The incorporation of considerations of responsibility that purport to insulate egalitarian thinkers from the critics of the so-called anti-egalitarian right has, however, exposed them to another now well-known battery of criticisms across a new front. In this regard the broad charge has been that this brand of responsibility-sensitive egalitarianism has been misguided in its full-blooded internalisation of the significance of responsible choice, with the implication that such a responsibility-sensitive view is committed to counterintuitive conclusions concerning which inequalities are just (Anderson 1999; Scheffler 2003, 2005; Wolff 1998). This paper offers an analysis of a particular responsibility-sensitive egalitarian manoeuvre in response to this kind of objection, and argues that the egalitarian response is in need of refinement in order to properly explain the putative fairness of certain inequalities.

The responsibility-sensitive egalitarian manoeuvre in question emphasises the distinction between two separable components of any given responsibility-sensitive egalitarian view. On the one hand a commitment to the unfairness of inequalities that are not the appropriate consequences of individuals' responsible choices; on the other hand a further account of which such consequences do indeed form fair inequalities. In order to better explain the sense in which those commitments are separable, I make use of the distinction Tim Scanlon draws between attributive and substantive responsibility (Scanlon 1998, 248). As I will understand that distinction here, substantive responsibility concerns liabilities and benefits for which individuals can be held to account, whereas attributive responsibility involves identifying some feature of persons that represent the grounds of those ascriptions of substantive responsibility. For the responsibility-sensitive egalitarian, then, inequalities resulting from persons being held substantively responsible for certain liabilities and benefits are fair only if those substantive responsibilities are connected in the right way with things for which persons are attributively responsible, usually thought to mean their responsible choices. Call this 'the principle of unfair inequality' - that individuals' own choices are necessary to render fair their being better or worse off than others. This makes choice a necessary condition for substantive responsibility but, alone, it does not tell us what gains and losses an individual actually ought to be held substantively responsible for.

The crucial egalitarian move, then, has been to explain that affirming the principle of unfair inequality does not entail any particular account of what individuals ought to be held substantively responsible for. A number of contemporary theorists have drawn attention to this (Stemplowska 2009; Olsaretti 2009; Dekker 2009; Arneson 1999). As Olsaretti (2009, 170-171) rightly explains, a commitment to the principle of unfair inequality is consistent with a wide variety of views of substantive responsibility. The question answered by the principle of unfair inequality is the question of what features of persons are the necessary grounds for fair inequality. Answering that question in the way that responsibility-sensitive egalitarians do, does not entail a particular answer to a distinct and further question - namely what costs and gains ought to accrue to the (potentially) inequality-justifying responsible choices. Rather, in addition to the principle of fair equality, we require what Olsaretti $(2009,167-173)$ calls a 'principle of stakes', 
namely a specification of what costs and gains individuals ought, in consequence of their choices, to be held substantively responsible for.

Emphasising the separability of the principle of unfair inequality from a principle of stakes is important because it can show that the rejection of any given principle of stakes does not necessarily counsel in favour of the rejection of responsibility-sensitive egalitarianism as such, only, at most, the particular conception distinguished by that principle of stakes. The defenders of responsibility-sensitive egalitarianism have suggested, then, that their view has, in many cases, only seemed to its critics to be vulnerable to a more wholesale rejection because its most prominent form - luck egalitarianism - has all too often been presented, by both advocates and critics alike, as if responsibility-sensitive egalitarianism in general entails a particular (and perhaps inadequately conceived) principle of stakes that may be vulnerable to those criticisms. ${ }^{1}$ By modifying the principle of stakes accordingly, a substantive alternative version of responsibility-sensitive egalitarian can be immunized against those of the criticisms that might have normative force against the luck egalitarian form.

The argument is a sound one, but it opens up the further question of how such an account of responsibility should be constructed, thereby birthing a range of different forms of responsibility-sensitive egalitarianism, united in their opposition to unchosen inequalities but distinguished from their familial counterparts according to the character of the account of responsibility they propose. In virtue of the fact that this argument is a relatively recent one, the associated literature is emergent. Those who have embraced this kind of move have offered differing suggestions as to how we should construct an account of responsibility and have done so, albeit legitimately, in relatively broad strokes. The present context, then, is one in which an important question looms for egalitarians who appreciate the value of responsibility; and one that can be answered in a range of different ways.

I contend that when justifying a principle of stakes there is a danger that egalitarian theory fails to explain the fairness of inequality. This is down to a failure to invoke reasons in favour of holding person responsible for the consequences of their choice that render fair rather than merely justify inequalities. This is particularly significant, or so I argue, given that among the most compelling considerations seeming to support a responsibility-sensitive form of egalitarianism, and underlying much of its pre-reflective appeal, is that of fairness. Though my argument here will express doubts about aspects of some of the answers that have been given, I intend this first and foremost as a constructive contribution to the task of developing such an egalitarian account of responsibility, and one that presents a challenge to be grappled with, rather than a reason to abandon the project.

To help frame the remaining analysis it's worth explicitly distinguishing between three separable commitments one might have with respect to a responsibility-sensitive understanding of the value of equality:

(1) The principle of unfair inequality: Inequalities that are not appropriately connected to individuals' own responsible choices are unfair.

(2) The principle of fair inequality: Inequalities that are appropriately connected to individuals' own responsible choices are not unfair.

(3) The principle of unfair equality: Equalities that are not appropriately connected to individuals' own responsible choices are unfair.

\footnotetext{
${ }^{1}$ For further work that defends responsibility-sensitive egalitarianism from such criticism see Arneson 2000; Knight 2005, 2015; Stemplowska 2009; Markovits 2008; Dekker 2009; Olsaretti 2009; Segall 2007
} 
The aforementioned principle of unfair inequality (1) holds only that fair inequality must be connected in the right ways to an individual's own responsible choices. The principle of fair inequality (2) holds that it is not unfair to hold individuals substantively responsible for some set of consequences whereas the principle of unfair equality (3) holds that it would be unfair to fail to hold individuals substantively responsible for some set of consequences. ${ }^{2}$ As such, eliminating fair inequalities would itself constitute an unfairness. Cohen $(2006,442)$ captures these principles in the following expression of luck egalitarianism: "So, in deference to fairness, the relevant egalitarian says that she's against inequalities in the absence of appropriately differential responsibility [principle (1)] (just as, she now realises, she is also against equalities in the presence of appropriately differential responsibility [principles (2) and (3))."3

In the following I reflect on difficulties that attend to a responsibility-sensitive egalitarian commitment to either the principle of fair inequality or the principle of unfair equality. In particular, I draw a parallel here between responsibility-sensitive egalitarian accounts of the fairness of inequality and a related difficulty in value theory known as the 'wrong kind of reasons problem'. To that end it's instructive to reflect on a relatively recent challenge brought by Cohen to the fairness of any inequalities, including inequalities licensed by forms of responsibility sensitive egalitarianism. I consider Cohen's argument in order to illuminate the nature of the challenge facing the responsibility-sensitive egalitarian view and to illustrate the kind of reasons to which egalitarians need to appeal in order for a principle of stakes to support the fairness of inequality specifically.

\section{Cohen on Fairness and Legitimacy}

In one of the few detailed and explicit analyses of the relation between fairness and inequality, Cohen (2011), in some of his later work, asks whether option luck ever preserves justice and fairness in distribution. In general terms his enquiry is whether, despite the fact that choices generate inequalities, those choices can preserve the fairness of a nevertheless unequal distribution. Framed in terms of the language of the foregoing, Cohen argues that all inequalities justified under any proposed principle of stakes embody a pro tanto unfairness. In service of this claim he reflects on two cases. In the first case, Cohen considers a group of people amongst which there is whatever counts as the relevantly equal distribution who unanimously will that all members of the group give half of their assets to two of the members of the group Sarah and Jane. In the second case, Cohen describes a situation in which persons A and B, again between which there is a perfectly equal distribution, decide to gamble half their total assets $(\$ 100,000$ total) against one another in a 50-50 toss of a coin. As a result of the 50-50 gamble, one person ends up with $\$ 150,000$ and the other person with $\$ 50,000$. Though in each case the resulting distributions are, Cohen $(2011,133)$ allows, 'legitimate' in the sense that "no one has a right to complain about the outcome," they are nevertheless unfair. ${ }^{4}$ To put this in the 'responsibility' terms of the paper: whilst it is legitimate to hold individuals substantively

\footnotetext{
${ }^{2}$ Principle 3 entails principle 2 because a commitment to the unfairness of equality entails a commitment to the fairness of those inequalities whose elimination would be required for that unfair equality.

${ }^{3}$ For an example of responsibility-sensitive egalitarianism that does not affirm the principle of unfair equality see Segall 2015, 352.

${ }^{4}$ For two further critical reflections on the justice of option luck inequalities, different from Cohen's, see Knight (2013) and Lippert-Rasmussen (2001)
} 
responsible for the outcomes of their choices, their substantive responsibility is not, in at least one important sense, either permitted or required by fairness. ${ }^{5}$

So, to be clear, Cohen holds that whilst inequalities that result from individuals' responsible choices might be legitimate in the sense that "no-one can justifiably complain about it on the grounds that it wrongs her," they nevertheless remain unfair in the sense that the distribution, by involving inequality, fails to be "appropriate to everything to which a distribution ought to be appropriate." Legitimacy, therefore, regards the nature of the complaint that a wronged party can bring against others whereas fairness concerns whether there is an inequality which represents a bad-making feature of the distribution. For Cohen, then, the inequality between the person who ends up with $\$ 50,000$ and the person who ends up with $\$ 150,000$ is legitimate in the sense that the former has no ground for complaint at being worse off, however it remains a bad-making feature of the distribution, and in that sense unfair, for the former to be worse off than the latter, even though their being so is a result of their own responsible choices. On this view responsible choices confer legitimacy without fairness.

Cohen's claim concerning fairness and legitimacy is relevant to the ambition of the paper in the following sense: it is an instance of the view that although inequalities can be justified (reasons can be offered that in some sense vindicate the inequalities; in Cohen's argument by eliminating grounds for a complaint) they are not, merely in virtue of being so justified, rendered fair. From this perspective, a principle of stakes can provide an account of the justified character of inequality without necessarily offering reasons for thinking those inequalities are fair.

Cohen's argument therefore offers a helpful backdrop to the chief contention of the paper inasmuch as it highlights the need to offer reasons in favour of the fairness of inequality specifically. To be clear, then, the intention is not to endorse Cohen's position but to use it to illustrate the kind of account that is necessary to explain the fairness of inequality. In this way, I will suggest that only certain kind of reasons are of the right character to ground a response to the challenge presented by Cohen. Before I arrive at the positive case for this conclusion, let me first explain why I think Cohen's doubts about the fairness of chosen inequalities should be taken seriously.

One quite understandable response to the Cohen position is to simply deny his claim and instead maintain that the resulting distributions in the gambling and Sarah-Jane cases are wholly fair rather than merely legitimate. That is, to deny that the inequality is a bad-making feature of the distribution in any respect. ${ }^{6}$ So one might simply maintain, pace Cohen, that not only do the responsible choices relieve the worse off individuals of any grounds for complaint at their being worse off, but furthermore that the choices render wholly fair the inequalities consequent on them. Although I take it that this is indeed a plausible position, I suggest we can and should do better than to simply assert this conviction against the Cohen view, as opposed to explaining and justifying it. Cohen's challenge itself is more than a simple intuitive denial of

\footnotetext{
${ }^{5}$ For a critical discussion of Cohen's claims see Williams (2013).

6 Andrew Williams' (2013) response to Cohen's argument presses the objection that, in virtue of the choices the worse off parties make, we have no reason at all to correct for the inequalities. Note, though, that the Cohen view, as I interpret it, does not necessarily tell us that we do have a reason, even a pro tanto one, to correct for the unfairness. His claim is strictly about the telic badness of the state of affairs and not directly about the normative reasons we have to remedy that badness. So if one has the firm intuition that we should not redistribute to eliminate such inequalities (or even that we have any reason to) this is strictly consistent (even if somewhat at odds) with Cohen's view that they remain unfair and in that sense bad. For a further discussion of the debate see Elford (2016)
} 
the fairness of chosen inequalities, so a mere appeal to competing intuition seems unsatisfactory if what we are looking for is a way of responding to his argument. Importantly, Cohen points out that the resulting distributions in his examples are no longer fair by the same criteria that made the initial distributions fair and asks why, if inequality is judged unfair by particular standard, choice makes a difference to the standard by which we judge the fairness of the subsequent distribution? Anchoring this analysis to the Sarah and Jane case, we can say the following: whilst members of a group unanimously will the redistribution of half of their assets to Sarah and Jane, creating inequality by way of making both Sarah and Jane better off than others, the initial distribution was a fair one because it was an equal one. Cohen rightly claims that this standard of fairness judges the resulting unequal distribution an unfair one. So Cohen does not merely motivate his position with these cases in a way that might provoke an intuitive stalemate against the adversary who embraces the fairness of inequality, but rather supports his move with a further argument: namely, if you judge something unfair because unequal, what is your story as to why some inequalities are fair and not others?

Now, there is a seemingly obvious response to Cohen's argument here, namely that the criteria by which the initial distribution is judged fair may not be, strictly, that there is no inequality but that there is no unchosen inequality. So, in the Sarah-Jane case, if unfairness pertains to involuntary disadvantage specifically, rather than disadvantage per se, then that criterion of fairness judges both the initial distribution between the Sarah-Jane group members fair and the subsequent and unequal distribution fair, on the grounds that neither entails any involuntary disadvantage. Whilst sensible, and, as I will later suggest, correct, this response doesn't so much offer a response to the Cohen position so much as it simply asserts what Cohen denies. After all, what are the grounds for saying that unchosen inequality is unfair whereas relevantly chosen inequality is not? We cannot appeal to the idea that choice legitimates otherwise unfair inequality for the obvious reason that Cohen's position is precisely that such choices thereby legitimate but do not render fair those chosen inequalities. So to claim, without further explanation, that chosen inequalities are fair would appear to simply stipulate a criterion for fairness at the cost of failing to engage Cohen's claim that choices only legitimate inequalities.

At this juncture an interlocutor might appeal to the notion of 'moral arbitrariness' to defend the position that the criterion for unfairness is unchosen inequality rather than inequality per se. Whereas unchosen inequalities are morally arbitrary in the sense that there is no justifying reason as to why they should obtain, chosen inequalities lack that quality of moral arbitrariness in the sense that there is a reason (choice) that justifies their obtaining. Again, I think this view is the right one, but it doesn't seem that it can, alone, form the basis of a successful response to the Cohen view. For even if this appeal to moral arbitrariness can successfully avoid the earlier worry that it simply asserts what Cohen denies, it seems problematic for other reasons. Primarily, there are a wide-range of reasons that might justify inequalities without thereby wholly eliminating the respect in which they are morally arbitrary (and, in that respect, unfair). For instance, it might be the case that some inequalities are to everyone's advantage in the sense that they enhance economic efficiency in ways that make everyone better off. That might well justify the inequalities in question but it will not, for most advocates of responsibilitysensitive egalitarianism, necessarily mean that those inequalities are through and through fair ones. To frame this in terms of the language of moral arbitrariness, one might say that allthings-considered the inequalities are not morally arbitrary, in the sense that there is a reason that justifies their obtaining, however this does not itself necessarily extinguish the sense in which they are, in one particular respect, morally arbitrary. So the idea that there is some 
reason that justifies inequality seems too capacious a criterion for inequalities being fair specifically. As will become clear, this very difficulty is precisely the problem that afflicts certain responsibility-sensitive egalitarian principles of stakes. Such accounts appeal to reasons that might justify the inequality on the basis of these further values to which they appeal but do not render fair in the relevant sense.

\section{Luck Egalitarianism and Fairness: Responding to Cohen's Challenge}

Cohen's claim that choice merely legitimates (but does not render fair) inequality is seemingly at odds with what many advocates of responsibility-sensitive egalitarianism want to maintain. Many want to say that choices (of the right sort, under the right conditions etc.) render inequalities fair through-and-through such that the choices the agents make wholly remove any unfairness-type badness that pertains to an unequal distribution. This reflects a commitment to what I have labelled the principle of fair inequality (2). What's more, as I intimate above, many advocates of responsibility-sensitive egalitarianism will want to affirm the further principle of unfair equality (3).

To see the attraction the principle of unfair equality for the luck egalitarian consider the standard luck egalitarian analysis of the coin-toss case. By stipulation both person A and person B enjoy initial equal brute luck of $\$ 100,000$. Their respective choices to gamble affect their respective quotas of option luck - person A, let's say, gains $\$ 50,000$ and person B loses $\$ 50,000$ - but do not affect their quotas of brute luck. This is because, again by stipulation, option luck in this case covers all and only the $\$ 50,000$ that is transferred between person A and person $\mathrm{B}$ in the gamble. Given this, it seems that any further redistribution from person A (now with $\$ 150,000$ ) to person $B$ (now with $\$ 50,000$ ) creates an inequality in the brute luck they enjoy. Insofar as luck egalitarians often claim that brute luck inequality is unfair they appear committed to the idea that equalising the distribution the results from the coin-toss case violates a pro tanto requirement of fairness. ${ }^{7}$

On this basis, then, it might seem that a luck egalitarian can explain the unfairness of equality in terms of the fairness of equal brute luck. Removing the inequality really entails an unequal (and for that reason unfair) distribution in the currency that is of relevant egalitarian concern: that of brute luck. ${ }^{8}$ This is too quick, however. ${ }^{9}$ Cohen's challenge can simply be pressed against the distinction between brute and option luck. We need to know why, given that brute luck inequality is judged unfair, option luck inequality is judged not only fair but, additionally, required by fairness. For the luck egalitarian option luck inequality is required by fairness in the sense that it is categorised outside of brute luck. Its elimination entails an inequality in brute luck; the latter of which is unfair on the luck egalitarian view. But to say that brute luck equality is required by fairness is therefore simply to articulate the shape of the luck

\footnotetext{
${ }^{7}$ It's worth noting that whilst luck egalitarianism is often formulated in terms of requiring brute luck equality, Elford (2013) has shown that there are some brute luck inequalities that luck egalitarianism does not have reason to object to. Elford's observations are, however, limited to noting that brute luck inequalities resulting from otheraffecting choices ought not to be judged unfair on luck egalitarian terms. He does not contest the idea that brute luck inequality more generally manifests unfair inequality. In the case under consideration, as the brute luck inequality that would be manifested by redistributing between A and B would not be, in the relevant way, a consequence of other-affecting choice it does not fall under the category of brute luck inequalities which Elford shows luck egalitarianism should not condemn as unfair.

${ }^{8}$ For an argument of this kind see Albertsen and Midtgaard (2014).

${ }^{9}$ Indeed, this seems to parallel the same question-begging response to Cohen already considered above.
} 
egalitarian view and not to explain why inequality resulting from choice is fair whereas inequality independent of choice is not.

Given Cohen's argument that unequal distributions cannot be judged fair by the same criteria that make initially equal distributions fair, we need to do more than resort to counterclaims, however intuitively persuaded we are of their force. What's more, a simple and unexplored appeal to our intuitive sense of the fairness of some chosen inequality does not necessarily tell us what underlies the intuition we have, and this is an important part of what is in question here. We might, for instance, have an intuition that murder is wrong without fully apprehending what it is, intuitively, that makes it seem wrong to us. Equally, we might have an intuition that chosen inequality is fair without fully apprehending what makes it seem fair to us. The question is, then, what one must affirm in order to coherently maintain that an inequality is fair whilst at the same time holding that unchosen inequality is unfair. This is important for the claim being offered in this paper because my claim is not that inequality is fair but about what one must affirm in order to coherently suppose that it is fair. That is, I'm not here offering a view as to whether advocates of responsibility-sensitive egalitarianism who affirm either the principle of fair inequality or the principle of unfair equality are right, against Cohen, that choices render otherwise unfair inequalities through and through fair ones but, rather, I am exploring the adequacy of some existing egalitarian work when it comes to answering this challenge.

\section{Fitting Attitudes and Wrong Kinds of Reason}

To underscore the importance of the challenge, and also allude to the kind of account which might be well-placed to successfully answer it, I want to draw attention to an illuminating parallel between the questions at stake here in respect of fairness and substantive responsibility, and a related issue in value theory. Fitting Attitude accounts of value analyse the nature of value in terms of the evaluative attitudes that are fitting responses to it. Under such accounts, for someone to be admirable or blameworthy is no more than for admiration or blame to be a fitting attitude towards them. The Fitting Attitude account of value is subject to what is sometimes referred to as the 'wrong kind of reasons problem' (D'Arms and Jacobson 2000; Rabinowicz and Rønnow-Rasmussen 2004). If my admiration for a tyrannical dictator will somehow save the lives of many innocent persons then it might be in some way right, good or appropriate for me to admire them but this doesn't make the dictator admirable. The kind of reasons adduced in this case are simply not of the right kind to support that notion. They are reasons to have or forbear from having a particular attitude towards the subject but they do not seem to be reasons that are connected in the right way to an evaluative judgment about that subject. Fitting Attitude accounts of value therefore face a challenge to discriminate between reasons that make something a fitting response and those which do not. The import of the wrong kind of reason problem is that it reflects the kind of error that advocates of responsibility-sensitive egalitarianism might be prone to make in their accounts of the fair substantive responsibility. That is that they fail to offer the right kind of reason to support the fairness of inequality.

Consider a couple of cases about which we can ask what it would be justified to hold persons substantively responsible for. Take a society divided along ethnic lines in which a high-profile public figure who is a member of a sizeable but minority ethnic grouping of the population is both guilty and correctly convicted (on appropriate evidential grounds, with due 
process etc.) of murder. His conviction is treated with widespread suspicion by the minority section of the population and if he is sentenced it will cause considerable and potentially catastrophic social upheaval. Or imagine a group of gamblers who win a series of successive high-stakes gambles but whose being rewarded to the extent of the expected payoffs is likely to have a dangerous destabilising effect on the society's economy. As explained, Olsaretti and others have compellingly argued that a commitment to the principle of fair equality does not entail a particular principle of stakes. For this reason it is open to responsibility-sensitive egalitarians to offer a principle of stakes which takes account of negative considerations like social upheaval or economic destabilisation. Under this way of thinking, the reasons we have to avoid social upheaval and economic instability, rather than being seen as reflecting values that compete for satisfaction with responsibility-sensitive equality, can be seen as values that partly determine what responsibility-sensitive equality requires. Instead of seeing them as external to a conception of responsibility-sensitive equality, they are values that are brought to bear on the very determination of what it is fair to hold persons substantively responsible for. ${ }^{10}$ By seeing such values as internal to the very value of equality and, in the language as I am using it, the determination of what inequalities are fair, egalitarians making this move risk being guilty of the same kind of error as those who appeal to the wrong kind of reason to admire the terrible dictator. That is, it's not clear that these are the right kinds of reason to explain the fairness of the inequality that the principle of stakes purported to capture.

Further cases illustrate the danger in question. A friend of mine cracks a joke that isn't funny. However he is of low self-confidence and a sensitive disposition and a less than positive reaction would be a further, potentially crushing blow to his fragile sense of worth. In this case perhaps I should laugh at the joke; it would be a good thing for his attempt at a joke to be substantively rewarded with a positive reaction from myself. That doesn't make the joke a funny one. Contrastively, A friend of mine tells a very clever joke but at the expense of an already vulnerable and marginalised mutual colleague. In this case perhaps I should not laugh at the joke; it would be a bad thing for her joke to be rewarded with a positive reaction from myself. In both cases the reasons whether to laugh or not - to substantively reward the jokes with a positive reaction - come apart from the reasons that bear on whether the jokes are funny or not. The reasons that bear on whether to laugh are simply a broader set than those that bear, more specifically, on whether the jokes are funny. Similarly, there are reasons which tell us what individuals should be held substantively responsible for - like whether rewarding or penalising such choices would cause social upheaval or have destabilising effects - which make up a broader set than the reasons that tell us whether it is fair to hold them substantively responsible.

\section{Stakes and Substantive Responsibility}

Although luck egalitarianism represents the view to which many contemporary forms of responsibility-sensitive egalitarianism ultimately owe their ancestry, luck egalitarians have tended to write without explicit reflection on the question of stakes. In view of this Olsaretti

\footnotetext{
${ }^{10}$ As Olsaretti (2009, 186, her emphasis) puts it: "the thought is not that these are costs which a responsible person is prima facie responsible for, and that further considerations enter into determining whether that person should, all things considered, be made to internalize those costs... but the question of stakes is a question about what responsibility itself requires... we are fleshing out, not constraining, the demands of responsibility."
} 
(2009, 173-182) takes up the task of seeking to sketch one from the piecemeal claims luck egalitarians make about the consequences persons should be held substantively responsible for as a consequence of their choices. Her conclusion is that luck egalitarianism assumes what she labels an 'equality-constrained contextualist' account of stakes. Under this view, in broad terms, persons are substantively responsible for whatever are the actual consequences of their choices that happen in a given context where i. that context of choice is one in which individuals (in general, not only those making the choice for which they are held substantively responsible) enjoy as large as possible an area of freedom and ii. their being held substantively responsible is constrained by the requirement that each enjoy equality of opportunity (for the relevant metric of advantage). ${ }^{11}$ Her chief objection to this account of stakes is that it places no constraints on the rights people lose (or jeopardise) as a consequence of their choices and that it lacks the internal resources to condemn potentially exploitative and hierarchical relations that might emerge from patterns of substantive responsibility taking certain forms. If I take a drive and leave my car unattended with the key in the ignition should I be held substantively responsible for its theft? If as a result of its theft the only way I can get home is by paying an opportunistic, exploitative passer-by a huge sum of money to give me a lift is this something that, on account of my informed and responsible choices, I should duly be held liable for?

In place of the luck egalitarian account of stakes, Olsaretti considers a consequentialist account of stakes where persons' substantive responsibility is determined by whatever is required to promote independently desirable outcomes. ${ }^{12}$ It should be evident that a consequentialist account of stakes is a paradigmatic failure as an account of what fairness requires in respect of persons' substantive responsibility. Connections between the question of the stakes of substantive responsibility and the 'wrong kind of reasons' problem are clearest in this case. As depicted by the examples of admiration for a dictator and laughing at a joke that isn't funny, we can have instrumental reasons to admire (to save innocents) and to laugh (to avoid damaging another's confidence) that do not tell us that something is admirable or funny. Similarly we can have instrumental reasons for holding persons substantively responsible for their choices in certain ways without those reasons rendering it fair to hold them substantively responsible in those ways.

To offer a further brief example, consider a society in which it is judged, on instrumental grounds, that we ought to hold persons liable for costs of their choices, however harsh, because failing to do so carries a significant danger that a damaging pattern of very risky and socially costly choices would obtain, the compensation for which would have a predictably very negative impact on long term economic growth. Now imagine that a steady cultural shift changes people's mind-sets such that under this current scheme of liability they begin to refrain taking risks of any sort, including some of the important entrepreneurial moves that would be essential to developing the economy in the longer term. Considerations of this sort counsel a shift in what persons ought to be held substantively responsible for as a result of their choices on this style of consequentialist account. Of course this need not necessitate a shift all the way from extreme liabilities to social insurance against every kind of risk; we can envisage a more fine-grained system of rules for substantive responsibility designed to encourage some socially valuable risk taking without entailing the worst elements of moral hazard. The question is not, however, whether we could institute such rules but what follows from saying that our account

\footnotetext{
${ }^{11}$ Peter Vallentyne (2002) offers a related discussion of the luck egalitarian position. See also Arneson 1999.

${ }^{12}$ It's important to note that Olsaretti does not offer either as accounts of what it is fair to hold persons substantively responsible for but simply what, substantively, responsibility requires.
} 
of stakes should vary in accord with cultural shifts of this kind and, in particular, whether such considerations bear at all on what it would be fair to hold people liable for; whether, and which, inequalities would be fair ones.

In response to the question of how to determine individuals' substantive responsibility, Zofia Stemplowska offers a further and promising account of stakes that I will refer to as a 'balance-of-interest' account. Stemplowska rightly accepts, with Olsaretti, that the question of the grounds for attributability and the question of stakes are different ones. Her way of putting this is to say that "the requirement of equality of options is not sophisticated enough on its own to put an end to worries about injustice resulting from leaving people who are responsible for their disadvantage to bear this disadvantage." (Stemplowska 2009, 243) ${ }^{13}$ On Stemplowska's view, broadly, the way to approach an account of the stakes for which persons should be justly held substantively responsible is by balancing the interests persons have in avoiding certain conduct (along with its attendant risks of disadvantage) with the interests people have in not being required to provide insurance against forms of disadvantage resulting from that conduct. ${ }^{14}$ As an illustration, she considers the choice between two car repair schemes, one of which offers free car repair for all cars, the other of which offers free car repair only for those cars that have been well-maintained by their owners. Stemplowska $(2009,249)$ concludes:

"if the interests that are served by being able to ignore car maintenance without losing access to free (at point of use) car repair are more important than the interest people have in retaining the resources that would be needed to offer free car repair, even if the car damage stems from a lack of car maintenance, then free accident repair should be offered."

My concern here is not to question whether Stemplowska has correctly identified the broad contours of what persons should be held substantively responsible for but to ask whether and in what ways her account of substantive responsibility has anything to do with fairness. If we assume for a moment that the balance of interests tells us to institute a repair scheme in which only maintained cars are repaired, does this make it the case that inequalities in access to free car repair service between owners of maintained and unmaintained cars are thereby fair inequalities? To press this in terms of Cohen's challenge, given that the criteria for a fair distribution is equality, why think that the decision of some car owners to leave their cars unmaintained means that their being worse is fair rather than legitimate?

Now, there are undoubtedly some considerations of fairness in play. For instance, car owners enjoy equality of opportunity for free car repair. However, of course, the thrust of Olsaretti and Stemplowska's work here is precisely that a commitment to equality of opportunity is separable from the requirement to hold persons substantively responsible for anything. As Stemplowska $(2009,247)$ herself explains, "equality of options is compatible with a wide, possibly infinite range of options attaching to the same conduct." It could be that Stemplowska's balance-ofinterest account tells us that we should not tax the car-maintaining and redistribute to the non-carmaintaining in order to eliminate inequality if and when their cars break down, but it's not clear that this is on the grounds of egalitarian reasons of fairness.

In support of this thought, consider an example Stemplowska herself offers to illustrate the intuitive salience of considerations of responsible choice. She calls to mind two single grown-up

\footnotetext{
${ }^{13}$ See also Stemplowska (2013)

${ }^{14}$ Ibid., p. 249.
} 
homeowners, equal in all relevant respects, each of whom lose their houses in separate fires. In the case of one of the men - Adam - the loss of his house was due to a faulty electrical cooker; in the case of the other - Ben - the fire was started by his leaving a candle burning near some curtains before he went out. Quite intuitively, Stemplowska maintains that, all else being equal, if we have only one further flat that cannot house them both it should go to Adam rather than Ben. No doubt it is likely that this judgement is supported by the balance of interest account. But isn't there something further and more basic the lies behind an intuition of this sort? I suspect that for many the intuition will be that Adam has a basic claim of fairness to favourable consideration over Ben for the provision of the sole replacement flat. That is, even if it transpires that the balance of everyone's interests supports offering a policy of free house provision that is always insensitive to the role that choices play in needing housing provision, there is some defeasible reason against giving Ben equal consideration with Adam in respect of the provision of the single available free house. ${ }^{15}$ In this way fairness should be understood as a (defeasible) constraint on stakes so that whatever our account of stakes is, it must take due account of there being some discrete, defeasible badness involved in some inequalities failing to obtain. ${ }^{16}$

\section{Conclusion}

Finally, let me respond to a possible objection to the foregoing analysis. It might be argued that I am just using the language of fairness in a stipulatively restrictive sense to exclude cases where inequalities are justified by a broader range of values. There is no harm, the argument might continue, in simply understanding the language of 'fairness' in a broader way to refer to all inequalities that individuals are deemed substantively responsible for as judged by whatever principle of stakes we favour. No doubt one can understand the language of fairness in this broader sense, however the argument of the paper is not primarily a linguistic one with respect to the use we make of the language of 'fairness'. Rather, I use the label of 'fairness' as a way of capturing the idea that a consideration is, as it were, internally related to the value of equality. Let me clarify that idea. Although responsibility-sensitive egalitarians hold that unchosen inequality is unfair, this is typically involves making what Cohen $(1989,908)$ calls a 'weak equalisandum' claim. Namely that "[people] should be as equal as possible in some dimension but subject to whatever limitations need to be imposed in deference to other values." So whilst unchosen inequality can be unfair, it can be justified by other values which bear on the determination of what, allthings-considered, we ought to do. Call this all-things-considered justification. Responsibilitysensitive egalitarians also characteristically claim that individuals' own responsible choices justify their being better or worse than others, in ways determined by the relevant account of stakes. However, this is not supposed to be an all-things-considered justification, but a claim that those inequalities are internally consistent with the value of equality. That is, the inequalities in question are putatively justified in the sense that they constitute inequalities that are in no way inconsistent with, and perhaps required by, that very value, rather than being in tension with equality but justified by other values. ${ }^{17}$ The foregoing discussion indicates how seeing such inequalities as

\footnotetext{
${ }_{15}$ To this extent the argument I am mounting does not represent a decisive reason to reject Stemplowska's balance-of-interest account but, rather, it is to draw attention to defeasible fairness costs associated with it.

${ }^{16}$ Indeed, Stemplowska (2009, 241, her emphasis) seems to reflect this thought in her own account when she says that "Equality, therefore, requires that the differential effects of choices should not be annulled by redistribution." Although this is put in terms of equality rather than fairness, the point is, I think, the same.

${ }^{17}$ Or, in Cohen's $(2011,138)$ terms, that the inequalities are "just, without qualification."
} 
internally related to the very value of equality (and in that sense fair) depends on invoking the 'right kind of reason' and that a wide range of considerations which seem that they might inform a given account of stakes will in fact justify inequality only in the external, all-things-considered sense.

It is a desideratum of responsibility-sensitive egalitarianism that it can offer an account of stakes that explains the fairness of inequality. So what kind of account of stakes must the responsibility-sensitive egalitarian offer to satisfy this? A more thoroughgoing exploration of such an account would extend beyond the reach of the paper, but I believe the analysis points towards a desert-based account. More specifically, a desert-based account of stakes is better suited precisely because the kind of reasons offered by a desert-account tend to relate to the nature of what is chosen and not to the wider contingent circumstances that are less intimately connected with the object of appraisal - the choice - that putatively transforms otherwise unfair inequality into inequality which is fair. ${ }^{18}$

Open Access This article is distributed under the terms of the Creative Commons Attribution 4.0 International License (http://creativecommons.org/licenses/by/4.0/), which permits unrestricted use, distribution, and reproduction in any medium, provided you give appropriate credit to the original author(s) and the source, provide a link to the Creative Commons license, and indicate if changes were made.

Publisher's Note Springer Nature remains neutral with regard to jurisdictional claims in published maps and institutional affiliations.

\section{References}

Albertsen A, Midtgaard SF (2014) Unjust Equalities. Ethical Theory Moral Pract 17:335-346

Anderson E (1999) What is the point of equality? Ethics 109:287-337

Arneson R (1989) Equality and equal opportunity for welfare. Philos Stud 56:77-93

Arneson R (1999) Equality of opportunity for welfare defended and recanted. J Polit Philos 7:488-497

Arneson R (2000) Luck egalitarianism and Prioritarianism. Ethics 110:339-349

Arneson R (2007) Desert and equality. In: Holtug N, Lippert-Rasmussen K (eds) Egalitarianism: new essays on the nature and value of equality. Oxford University Press, Oxford, pp 262-293

Cohen GA (1989) On the currency of egalitarian justice. Ethics 99:906-944

Cohen GA (2006) Luck and equality: a reply to Hurley. Philos and Phenomenol Res 72:439-446

Cohen GA (2011) Fairness and legitimacy in justice, and: does option luck ever preserve justice? In: Otsuka M (ed) On the Currency of Egalitarian Justice and Other Essays in Political Philosophy. Princeton University Press, Princeton, pp 124-143

D'Arms J, Jacobson D (2000) The moralistic fallacy: on the 'appropriateness' of emotions. Philos Phenomenol Res 61:65-90

Dekker T (2009) Choices, consequences and desert. Inquiry 52:109-126

Dworkin R (1981) What is equality? Part 2: equality of resources. Philos Public Aff 10:283-345

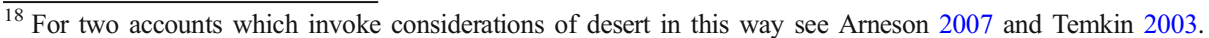
Interestingly, Temkin maintains that desert is a narrower notion than (comparative) fairness, so something other than desert is necessary to explain the fairness of inequality in the wider cases. Olsaretti $(2009,183-185)$ also considers a desert-based account of stakes and the advantages of such an account for explaining the fairness of inequality are highlighted by her conclusion that the notion of desert is well-placed to answer some of the shortcomings of the consequentialist account that I have pointed to. Although she falls short of affirming a desert account I suspect that if we think that the fairness of inequality is at stake, and we believe that choices do indeed render fair such inequality then it is considerations of desert that are most likely to furnish us with a coherent and compelling answer and avoid the 'wrong kind of reasons' difficulties discussed in the above.
} 
Elford G (2013) Equality and other-affecting choice: why luck egalitarianism does not require brute luck equality. Ethical Theory Moral Pract 16:139-149

Elford G (2016) Preserving fairness: Williams against Cohen on just inequality. Crit Rev Int Soc Pol Phil 19:699_ 713

Knight C (2005) In Defence of luck egalitarianism. Res Publica 11:55-73

Knight C (2013) Egalitarian justice and expected value. Ethical Theory Moral Pract 16:1061-1073

Knight C (2015) Abandoning the abandonment objection: luck egalitarian arguments for public insurance. Res Publica 21:119-135

Lippert-Rasmussen K (2001) Egalitarianism, option luck, and responsibility. Ethics 111:548-579

Markovits D (2008) Luck egalitarianism and political solidarity. Theoret Inq in Law 9:271-308

Olsaretti S (2009) Responsibility and the Consequences of Choice. Proc Aristot Soc 109:165-188

Rabinowicz W, Rønnow-Rasmussen T (2004) The strike of the demon: on fitting pro-attitudes and value. Ethics $114: 391-423$

Scanlon T (1998) What we owe to each other. Harvard University Press, Cambridge

Scheffler S (2003) What is egalitarianism? Philos Public Aff 31:5-39

Scheffler S (2005) Choice, circumstances and the value of equality. Pol Philos Econ 4:5-28

Segall S (2007) In solidarity with the imprudent: a defense of luck egalitarianism. Soc Theory Pract 33:177-198

Segall S (2015) What's so egalitarian about luck egalitarianism? Ratio XXVIII:349-368

Stemplowska Z (2009) Making justice sensitive to responsibility. Political Studies 57:237-259

Stemplowska Z (2013) Rescuing Luck Egalitarianism. J Soc Philos 44:402-419

Temkin L (2003) Egalitarianism defended. Ethics 113:764-782

Vallentyne P (2002) Brute luck, option luck and equality of initial opportunities. Ethics 112:529-557

Williams A (2013) How gifts and gambles preserve justice. Econ Philos 29:65-85

Wolff J (1998) Fairness, respect and the egalitarian ethos. Philos Public Aff 27:97-122 